\title{
Genomic insights into the thiamin metabolism of Paenibacillus thiaminolyticus NRRL B-4156 and P. apiarius NRRL B-23460
}

\author{
David Sannino and Esther R. Angert ${ }^{*}$ (D)
}

\begin{abstract}
Paenibacillus thiaminolyticus is the model organism for studying thiaminase I, an enigmatic extracellular enzyme. Originally isolated from the feces of clinical patients suffering from thiamin deficiency, P. thiaminolyticus has been implicated in thiamin deficiencies in humans and other animals due to its ability to produce this thiamindegrading enzyme. Its close relative, P. apiarius, also produces thiaminase I and was originally isolated from dead honeybee larvae, though it has not been reported to be a honeybee pathogen. We generated draft genomes of the type strains of both species, P. thiaminolyticus NRRL B-4156 and P. apiarius NRRL B-23460, to deeply explore potential routes of thiamin metabolism. We discovered that the thiaminase I gene is located in a highly conserved operon with thiamin biosynthesis and salvage genes, as well as genes involved in the biosynthesis of the antibiotic bacimethrin. Based on metabolic pathway predictions, P. apiarius NRRL B-23460 has the genomic capacity to synthesize thiamin de novo using a pathway that is rarely seen in bacteria, but $P$. thiaminolyticus NRRL B-4156 is a thiamin auxotroph. Both genomes encode importers for thiamin and the pyrimidine moiety of thiamin, as well as enzymes to synthesize thiamin from pyrimidine and thiazole.
\end{abstract}

Keywords: Thiaminase I, Paenibacillus thiaminolyticus, Paenibacillus apiarius, Paenibacillus dendritiformis, Thiamin, Hydroxymethyl pyrimidine

\section{Introduction}

Prior to World War II, beriberi and other vitamin deficiencies were prevalent in Japan and linked to a diet composed almost entirely of polished rice [1]. Additionally, it was discovered that certain fish and shellfish contained no thiamin and moreover any thiamin added to these raw foodstuffs was quickly destroyed [2]. While investigating potential links between the intestinal microbiota and beriberi, Shibata and colleagues found that when thiamin was added to feces or infused in the colon of patients suffering thiamin deficiency, the added thiamin disappeared [2, 3]. The thiaminase enzyme responsible for the destruction of thiamin in feces and in animal tissues was discovered shortly thereafter. Several bacteria, including Paenibacillus thiaminolyticus, were isolated by Matsukawa and Misawa from patient fecal samples with thiaminase activity [2]. The discovery of thiaminase producing bacteria facilitated extensive research efforts to understand the biochemistry of thiaminase and the biology of $P$. thiaminolyticus [4].

\footnotetext{
* Correspondence: era23@cornell.edu
}

Cornell University, Ithaca, NY, USA
Paenibacillus thiaminolyticus became a model system for studying the secreted bacterial thiaminase now known as thiaminase I [5-10]. Thiaminase I catalyzes the base substitution of the thiazole moiety of thiamin with numerous organic nucleophiles such as pyridine, quinolone, or compounds containing a sulfhydryl group, like cysteine [2, 10,11]. Early studies of this extracellular enzyme found that thiaminase I activity is repressed when high concentrations of thiamin are added to cultures and culture supernatant $[8,9]$. The crystal structure of $P$. thiaminolyticus thiaminase I revealed that the $42 \mathrm{kDa}$ protein has a catalytic cysteine residue and the protein is structurally similar to the group II periplasmic binding proteins, particularly the thiaminbinding protein TbpA in E. coli [12]. We recently found that Paenibacillus apiarius also has thiaminase I activity (unpublished). This close relative of $P$. thiaminolyticus was originally isolated from the larvae of dead honeybees, although it was not the causative agent of their death [13]. Despite the extensive biochemical and mechanistic understanding of the enzyme, the biological function and context in which $P$. apiarius, $P$. thiaminolyticus and other 
thiaminase I producers use thiaminase I remains a mystery [14].

Although thiaminase I activity is found in plants such as bracken fern [15] and nardoo [16], as well as in animals such as crustaceans, ruminants, and fish, the only confirmed producers of thiaminase I are microbial, including one eukaryote, the amoeba Naegleria gruberi $[15,17,18]$. Thiaminase I activity in food contributes to thiamin deficiency in animals and is implicated in Early Mortality Syndrome in salmonids in the Great Lakes and Baltic Sea [18]. A link between P. thiaminolyticus and this thiamin deficiency syndrome has been suggested, as $P$. thiaminolyticus has been isolated from the viscera of alewife, a fish with high thiaminase activity that is a food source for Great Lakes salmonids. Additionally, it was demonstrated that Early Mortality Syndrome could be induced in lake trout fed an experimental diet supplemented with $P$. thiaminolyticus $[18,19]$. As with humans, $P$. thiaminolyticus is not always isolated from intestinal contents of fish with high thiaminase I activity so other sources of the enzyme likely impact thiamin metabolism in populations of animals [20].

Thiaminase I enzymes are not widely distributed in the microbial world and are produced by a small subset of phylogenetically diverse microorganisms. By sequencing the genomes of the type strains, $P$. thiaminolyticus NRRL B-4156 and its relative P. apiarius NRRL B-23460, we aim to establish the genomic context of the thiaminase I gene to help gain a better understanding of the biological function of the enzyme. The draft genomes have helped uncover the routes of vitamin B1 metabolism available to these bacteria, which will help inform our model of the ecological role of thiaminase I, and perhaps its contribution to vitamin deficiencies in animals.

\section{Organism information}

\section{Classification and features}

The original isolate of $P$. thiaminolyticus, classified as Bacillus thiaminolyticus, was obtained from the feces of a Japanese patient suffering from thiamin deficiency and chronic constipation [2]. Additional strains of P. thiaminolyticus have been isolated from fecal samples of healthy human subjects from Kyoto and Ube City, as well as those with symptoms of thiamin deficiency $[2,4]$. Aside from being associated with human feces, $P$. thiaminolyticus reportedly induced bacteremia in an 80year-old hospital patient undergoing hemodialysis for end-stage renal disease [21]. Strains of $P$. thiaminolyticus have been found in the alimentary tract and feces of thiamin deficient lambs, ewes, and sheep [22], and from the viscera of Lake Michigan alewives [18, 23]. Other isolates have been recovered from honeybees [24] and from soil [4]. Growth of P. thiaminolyticus on defined minimal media requires the addition of thiamin or the two moieties that form thiamin [6]. Like some strains of $P$. thiaminolyticus, $P$. apiarius was isolated from dead honeybee larvae, adults, and honeycombs [13]. It is not suspected to be a honeybee pathogen as $P$. apiarius spores fed to larvae and adults did not induce death or any obvious pathology [13]. A few P. thiaminolyticus strains have been erroneously classified as $P$. apiarius [25]. In contrast to $P$. thiaminolyticus, $P$. apiarius has not been studied extensively.

Both species are rod-shaped endospore formers and produce a single ellipsoid endospore in a swollen sporangium, with the spore coat of $P$. apiarius described as unusually thick [25]. The spore produced by $P$. apiarius has a rectangular outline, unlike the more ellipsoid shape seen in P. thiaminolyticus [25]. P. apiarius cells are slightly larger than $P$. thiaminolyticus cells as they range from 3.0-5.0 $\mu \mathrm{m}$ in length and $0.7-0.8 \mu \mathrm{m}$ in width, while $P$. thiaminolyticus cells are $2.0-3.0 \mu \mathrm{m}$ long and $0.5-1.0 \mu \mathrm{m}$ wide [24, 25] (Fig. 1). The predominant cellular fatty acid in both $P$. apiarius and $P$. thiaminolyticus is anteiso- $\mathrm{C}_{15: 0}$ [25], and both have a Gram-positive cell wall. General features of the two organisms are summarized in Tables 1 and 2 .

These paenibacilli were originally classified as members of the genus Bacillus, based on their morphological features and biochemical properties, although $P$. apiarius, $P$. thiaminolyticus and their close relatives were not included in the original description of the genus [26]. Due to their similar phenotypes, six strains of Bacillus thiaminolyticus were classified in the $B$. apiarius species group, but $16 \mathrm{~S}$ rRNA gene analysis revealed that $B$. apiarius isolates form two separate clades [25]. This phylogenetic analysis further provided support for reclassifying $B$. apiarius strains as Paenibacillus apiarius and those clustering with $B$. thiaminolyticus were renamed [25]. Shortly after, $B$. thiaminolyticus and numerous other Bacillus species were reclassified as Paenibacillus spp. [27]. Both P. apiarius and $P$. thiaminolyticus share the hallmarks of other Paenibacillus species in that they are facultative anaerobes, that grow well on nutrient agar at neutral $\mathrm{pH}$ but inclusion of a fermentable sugar, such as glucose, will enhance growth [28]. These paenibacilli produce similar colonies when grown for $24 \mathrm{~h}$ on tryptic soy agar and appear circular, entire, and translucent, but are distinguishable by yellow pigmentation of $P$. apiarius colonies, which is not seen with $P$. thiaminolyticus. Both P. apiarius and P. thiaminolyticus can respire anaerobically using nitrate as an electron acceptor. Both can break down disaccharides and some polysaccharides [27]. Carbon sources that support growth and complex organic compounds that $P$. apiarius and $P$. thiaminolyticus can hydrolyze are listed in Tables 1 and 2 , respectively. Unlike $P$. apiarius, $P$. thiaminolyticus can ferment lactose as well as the sugar alcohols Dmannitol and D-sorbitol [24, 25]. Another distinguishing 


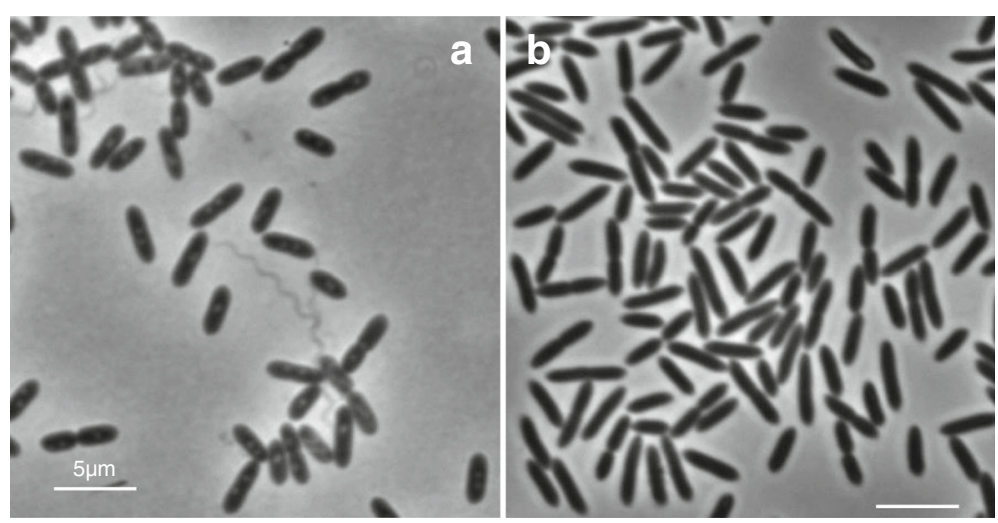

Fig. 1 Phase-contrast micrographs of $P$. apiarius NRRL B-23460 and $P$. thiaminolyticus NRRL B-4156. a Depicts P. apiarius NRRL B-23460 cells grown in TSB for $24 \mathrm{hr}$. at $30^{\circ} \mathrm{C}$. b Depicts P. thiaminolyticus NRRL B-4156 cells grown in TSB for $24 \mathrm{hr}$. at $37^{\circ} \mathrm{C}$. Scale bars represent $5 \mu \mathrm{m}$

characteristic is the ability of $P$. thiaminolyticus to produce indole. The ability to decompose thiamin was considered a distinct feature of $P$. thiaminolyticus [24] but can no longer be used to differentiate it from $P$. apiarius or $P$. dendritiformis (unpublished). P. apiarius is closely related to the honeybee pathogen $P$. alvei, while $P$. thiaminolyticus is very closely related to $P$. dendritiformis, $P$. popilliae, and $P$. lentimorbus, the latter two species are insect pathogens, responsible for milky spore disease in Japanese beetles [29]. Recently it was discovered that paenibacilli are distinct from Bacillus spp. in the arrangement of genes around the chromosomal origin of replication [30]. Paenibacilli code for a YheC/D family protein, designated orf14, between the gyrA and gyrB genes while Bacillus species do not have this intervening gene. Our maximum likelihood 16S rRNA gene tree generated by FastTree 2.1 [31] is congruent with these studies (Fig. 2). The tree also indicates that $P$. thiaminolyticus OSY-SE is a strain of P. apiarius.

The present study was used to learn more about the genomic context of the thiaminase I gene and thiamin metabolism in these paenibacilli and their close relative P. dendritiformis $\mathrm{C} 454$ which has a published draft genome [32].

\section{Genome sequencing information}

\section{Genome project history}

Both P. thiaminolyticus NRRL B-4156 and P. apiarius NRRL B-23460 were acquired from the Agricultural Research Service Culture Collection. The DNA was sequenced in April of 2014. Raw reads were assembled using SPAdes version 3.5 [33]. The contigs were quality filtered by size and coverage. Completeness and heterogeneity were assessed using CheckM [34] and the draft genomes were submitted to Genoscope for annotation with the MicroScope platform [35]. The assembled draft genomes were submitted to the Joint Genome Institute
Integrated Microbial Genomes analysis system [36] in October 2016 for annotation. Project summaries are provided in Table 3.

\section{Growth conditions and genomic DNA preparation}

Both $P$. apiarius NRRL B-23460 and P. thiaminolyticus NRRL B-4156 were grown in tryptic soy broth with shaking, at $30^{\circ} \mathrm{C}$ and $37^{\circ} \mathrm{C}$, respectively. Genomic DNA was extracted using a protocol typically used for isolating high molecular weight DNA from Bacillus subtilis [37]. Briefly, cells were lysed with lysozyme and sodium n-lauryl sarcosine. DNA was extracted using phenol:chloroform, and precipitated using ethanol. Near-complete 16S rRNA genes were amplified from the genomic DNA. Sequences were determined and compared with published sequences available in GenBank. The whole genome sequencing projects for $P$. apiarius NRRL B-23460 and P. thiaminolyticus NRRL B-4156 were deposited in DDBJ/EMBL/GenBank under accession numbers NDGJ00000000 and NDGK00000000, respectively.

\section{Genome sequencing and assembly}

Illumina MiSeq $2 \times 250$ sequencing reactions were conducted on the two DNA samples at the Cornell University Institute of Biotechnology in Ithaca, NY. This resulted in 3,704,766 reads for the $P$. apiarius NRRL B-23460 genome and 4,092,728 reads for the $P$. thiamonolyticus NRRL B4156 genome. The reads were quality checked and assembled using SPAdes 3.5 [33]. Contigs were filtered based on coverage (above 50x) and size (above 1000 bp). CheckM [34] was used to determine genome completeness and revealed that the $P$. apiarius NRRL B-23460 genome is 99.73\% complete with no strain heterogeneity, while the $P$. thiaminolyticus genome is $99.68 \%$ complete with no strain heterogeneity. 
Table 1 Classification and general features of P. apiarius NRRL B-23460 [53]

\begin{tabular}{|c|c|c|c|}
\hline MIGS ID & Property & Term & Evidence code ${ }^{a}$ \\
\hline & Classification & Domain Bacteria & TAS [54] \\
\hline & & Phylum Firmicutes & TAS [55] \\
\hline & & Class Bacilli & $\operatorname{TAS}[56,57]$ \\
\hline & & Order Bacilliales & TAS [58] \\
\hline & & Family Paenibacilliaceae & TAS [56] \\
\hline & & Genus Paenibacillus & TAS $[26,59]$ \\
\hline & & Species apiarius & TAS [25] \\
\hline & & $\begin{array}{l}\text { (Type) strain: NRRL } \\
B-23460^{T}\end{array}$ & \\
\hline & Gram stain & Positive & TAS [25] \\
\hline & Cell shape & Rod & TAS [25] \\
\hline & Motility & Motile & TAS [25] \\
\hline & Sporulation & $\begin{array}{l}\text { Endospores with thick } \\
\text { coats }\end{array}$ & TAS [25] \\
\hline & Temperature range & $15-40^{\circ} \mathrm{C}$ & TAS [25] \\
\hline & Optimum temperature & $28^{\circ} \mathrm{C}$ & TAS [25] \\
\hline & $\mathrm{pH}$ range; Optimum & Not reported & \\
\hline & Carbon source & $\begin{array}{l}\text { D-glucose, D-galactose, cellobiose, } \\
\text { maltose, melibiose, sucrose, trehalose, } \\
\text { salicin; can hydrolyize starch, casein }\end{array}$ & TAS [13] \\
\hline MIGS-6 & Habitat & $\begin{array}{l}\text { Soil and honeybee } \\
\text { associated }\end{array}$ & TAS [13] \\
\hline MIGS-6.3 & Salinity & $5 \% \mathrm{NaCl}(w / v)$ & TAS [25] \\
\hline MIGS-22 & Oxygen requirement & facultative & TAS [13] \\
\hline MIGS-15 & Biotic relationship & free-living & TAS [13] \\
\hline MIGS-14 & Pathogenicity & non-pathogen & TAS [25] \\
\hline MIGS-4 & Geographic location & Manitoba, Canada & TAS [13] \\
\hline MIGS-5 & Sample collection & 1950s & TAS [13] \\
\hline MIGS-4.1 & Latitude & Not reported & \\
\hline MIGS-4.2 & Longitude & Not reported & \\
\hline MIGS-4.4 & Altitude & Not reported & \\
\hline
\end{tabular}

${ }^{a}$ Evidence codes - IDA: Inferred from Direct Assay; TAS: Traceable Author Statement (i.e., a direct report exists in the literature); NAS: Non-traceable Author Statement (i.e., not directly observed for the living, isolated sample, but based on a generally accepted property for the species, or anecdotal evidence). These evidence codes are from the Gene Ontology project [60]

\section{Genome annotation}

Gene calling and annotations for $P$. apiarius NRRL B-23460 and $P$. thiaminolyticus NRRL B-4156 were developed by both the MicroScope platform [35] and IMG [36], P. dendritiformis C454 was annotated with MicroScope only. Annotations of interest were independently verified using the Uniprot (Swissprot and TrEMBL) database and BLAST. Ambiguous gene sequences were compared to their B. subtilis counterparts to further help identify a putative function. DELTA-BLAST was used to determine functional domains of uncharacterized proteins, and confirm those of characterized proteins of interest.

\section{Genome properties}

The draft genome for $P$. apiarius NRRL B-23460 is $5,404,821$ bp $(50.49 \% \mathrm{G}+\mathrm{C})$ and comprises 51 contigs. The largest contig is $827,142 \mathrm{bp}$, and the smallest is $1010 \mathrm{bp}$ in length. The N50 of the genome is 280,248. IMG identified 4957 genes in the genome. Of those genes, 4822 encode for proteins $(97.28 \%), 22$ are rRNA genes $(0.44 \%), 76$ are tRNA genes $(1.53 \%)$, and no pseudogenes were discovered. Of the 22 rRNA genes identified, seven are 5S, ten are 16S, and five are $23 \mathrm{~S}$ genes. The draft genome for $P$. thiaminolyticus is $6,547,709$ bp $(53.64 \% \mathrm{G}+\mathrm{C})$, contains 48 contigs, with the largest contig being 1,172,336 bp and the smallest being 1148 bp. The N50 is 254,830 bp. For this genome 5880 
Table 2 Classification and general features of P. thiaminolyticus NRRL B-4156 [53]

\begin{tabular}{|c|c|c|c|}
\hline MIGS ID & Property & Term & Evidence code ${ }^{\mathrm{a}}$ \\
\hline & Classification & Domain Bacteria & TAS [54] \\
\hline & & Phylum Firmicutes & TAS [55] \\
\hline & & Class Bacilli & $\operatorname{TAS}[56,57]$ \\
\hline & & Order Bacilliales & TAS [58] \\
\hline & & Family Paenibacilliaceae & TAS [56] \\
\hline & & Genus Paenibacillus & $\operatorname{TAS}[26,59]$ \\
\hline & & Species thiaminolyticus & TAS [24] \\
\hline & & (Type) strain: NRRL B-4156 ${ }^{T}$ & \\
\hline & Gram stain & Positive & TAS [24] \\
\hline & Cell shape & Rod & TAS [24] \\
\hline & Motility & Motile & TAS [24] \\
\hline & Sporulation & endospores & TAS [24] \\
\hline & Temperature range & $20-45^{\circ} \mathrm{C}$ & TAS [24] \\
\hline & Optimum temperature & $28^{\circ} \mathrm{C}$ & TAS [24] \\
\hline & $\mathrm{pH}$ range; Optimum & Not reported & \\
\hline & Carbon source & $\begin{array}{l}\text { D-glucose, D-fructose, D-galactose, } \\
\text { D-ribose, lactose, cellobiose, maltose, } \\
\text { mannose, melibiose, sucrose, trehalose, } \\
\text { salicin; can hydrolyze starch, casein }\end{array}$ & TAS [24] \\
\hline MIGS-6 & Habitat & Soil, animal associated & TAS [24] \\
\hline MIGS-6.3 & Salinity & $5 \% \mathrm{NaCl}(\mathrm{w} / \mathrm{v})$ & TAS [24] \\
\hline MIGS-22 & Oxygen requirement & facultative & TAS [24] \\
\hline MIGS-15 & Biotic relationship & free-living & TAS [24] \\
\hline MIGS-14 & Pathogenicity & non-pathogen (1 case in humans) & NAS $[21,24]$ \\
\hline MIGS-4 & Geographic location & Japan & TAS [24] \\
\hline MIGS-5 & Sample collection & $1940 \mathrm{~s}$ & TAS [24] \\
\hline MIGS-4.1 & Latitude & Not reported & \\
\hline MIGS-4.2 & Longitude & Not reported & \\
\hline MIGS-4.4 & Altitude & Not reported & \\
\hline
\end{tabular}

${ }^{a}$ Evidence codes - IDA: Inferred from Direct Assay; TAS: Traceable Author Statement (i.e., a direct report exists in the literature); NAS: Non-traceable Author Statement (i.e., not directly observed for the living, isolated sample, but based on a generally accepted property for the species, or anecdotal evidence). These evidence codes are from the Gene Ontology project [60]

genes were identified as protein encoding (97.89\%), with 21 rRNA genes (0.36\%), 77 tRNA genes (1.31\%), and no pseudogenes $(0.00 \%)$. Amongst the rRNA genes, five $5 \mathrm{~S}$, nine $16 \mathrm{~S}$, and seven $23 \mathrm{~S}$ genes were identified. More details of these draft genomes are given in Table 4, and the CoG analyses are summarized in Tables 5 and 6.

\section{Insights from the genome sequence}

We investigated the potential thiamin biosynthetic capabilities of $P$. apiarius NRRL B-23460, P. thiaminolyticus NRRL B-4156, and P. dendritiformis C454 using the annotations and metabolic pathways generated by MicroScope. Typically in bacteria, TPP, the active cofactor, is formed from two phosphorylated moieties, THZ-P and HMP-PP. The thiazole moiety is derived from the glycolysis products pyruvate and G3P, a sulfur from cysteine, and either tyrosine (in E. coli) or glycine (in B. subtilis) [38]. The formation of THZ-P requires a suite of proteins including deoxy-dxylulose 5-phosphate synthase (Dxs), a sulfur donor protein (NifS or IscS), adenyltransferase (ThiF), sulfur carrier protein (ThiS), thiazole synthase (ThiG), thiazole biosynthesis protein $\mathrm{ThiH}$ or glycine oxidase $\mathrm{ThiO}$, and in some cases an aromatase (TenI) [38]. The pyrimidine moiety is derived from AIR, an intermediate in purine biosynthesis. HMP synthase (ThiC) and HMP kinase (ThiD) are required to form HMP-PP [38]. Thiamin phosphate synthase (ThiE) combines THZ-P and HMP-PP to form TMP, which is then phosphorylated by thiamin phosphate kinase (ThiL), forming TPP [38].

The $P$. apiarius draft genome contains all of the genes required to make THZ-P (Fig. 3); thiG, thiO, thiS, and tenI are located in an operon putatively regulated by a TPP- 


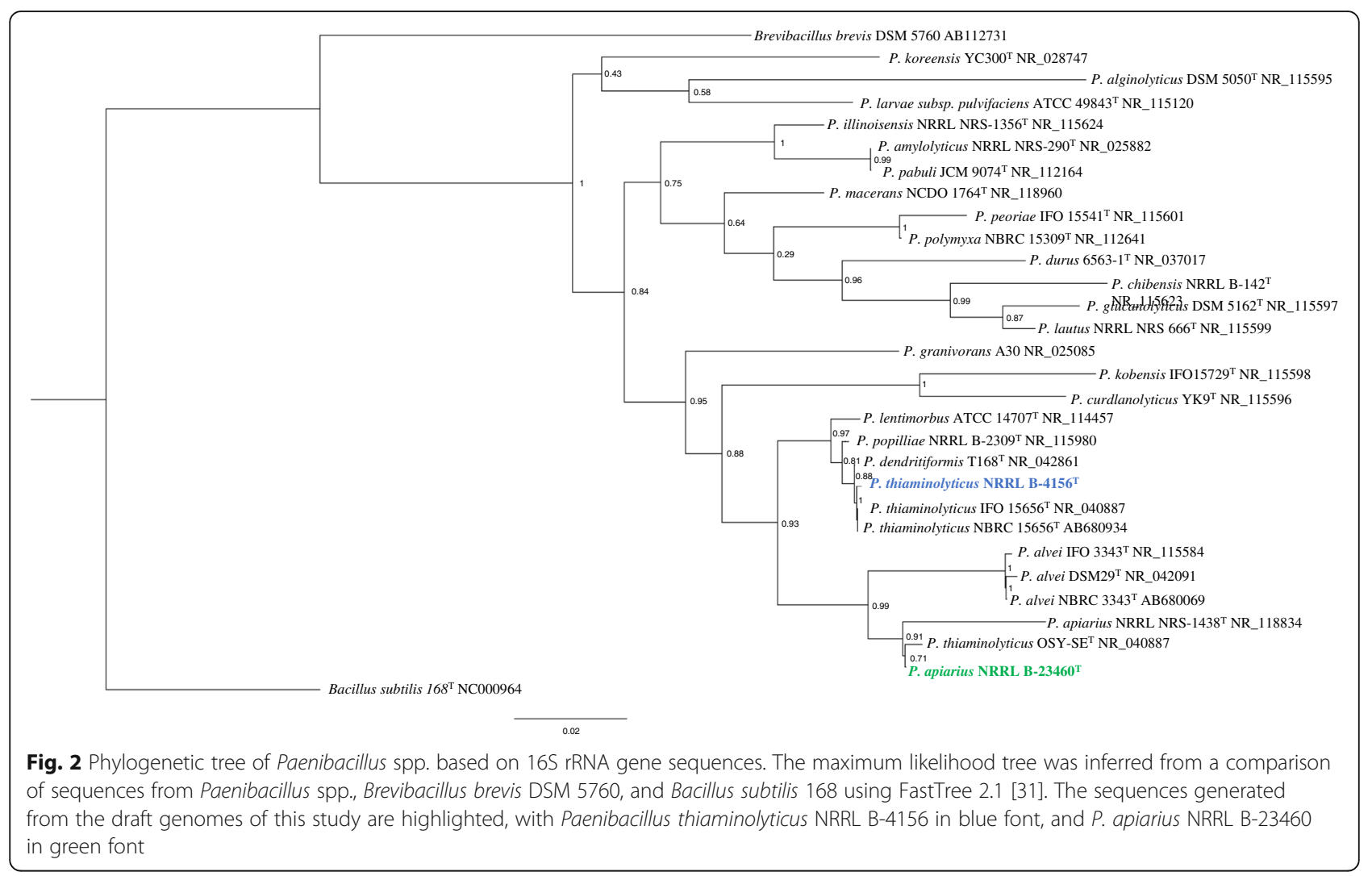

binding riboswitch. The presence of thiO suggests that NRRL B-23460 uses glycine to generate the thiazole moiety. With thiC and thiD present, it appears competent for HMP-PP biosynthesis (3). The genome contains thiE but lacks thiL for the terminal phosphorylation; however, it contains a putative TPK. Plants, fungi, and a few species of bacteria, use a different thiamin biosynthesis strategy where thiamin monophosphate is dephosphorylated to thiamin, and then converted to TPP by a TPK [39]. The genome content of $P$. apiarius NRRL B-23460 suggests that it synthesizes thiamin in this manner. Hasnain and colleagues recently demonstrated that HAD-superfamily enzymes of the subfamily IA in plants and some bacteria catalyze the dephosphorylation of TMP [39]. In bacteria, these hydrolase genes are either fused to a thiamin biosynthesis gene, like thiD or thiE, or these genes are located in

Table 3 Project information

\begin{tabular}{llll}
\hline MIGS ID & Property & Term (P. apiarius) & Term (P. thiaminolyticus) \\
\hline MIGS 31 & Finishing quality & Draft & Draft \\
MIGS-28 & Libraries used & TruSeq & TruSeq \\
MIGS 29 & Sequencing platforms & Illumina MiSeq & Illumina MiSeq \\
MIGS 31.2 & Fold coverage & $150 \times$ & $150 \times$ \\
MIGS 30 & Assemblers & SPAdes 3.5 & SPAdes 3.5 \\
MIGS 32 & Gene calling method & IMG and MicroScope & IMG and MicroScope \\
& Locus Tag & Ga0138518 & Ga0138519 \\
& Genbank ID & NDGJ00000000 & NDGK00000000 \\
& GenBank Date of Release & $05 / 31 / 2017$ & $05 / 31 / 17$ \\
& GOLD ID & Ga0138518 & Ga0138519 \\
MIGS 13 & BIOPROJECT & PRJNA382554 & PRJNA382555 \\
& Source Material Identifier & Insect associated & Human associated \\
\hline
\end{tabular}


Table 4 Genome and annotation statistics for $P$. apiarius and $P$. thiaminolyticus

\begin{tabular}{|c|c|c|c|c|}
\hline \multirow[t]{2}{*}{ Attribute } & \multicolumn{2}{|c|}{ P. apiarius NRRL B-23460 } & \multicolumn{2}{|c|}{ P. thiaminolyticus NRRL B-4156 } \\
\hline & Value & $\%$ of Total & Value & $\%$ of Total \\
\hline Genome size (bp) & $5,404,821$ & 100.00 & $6,537,496$ & 100.00 \\
\hline DNA coding (bp) & $4,642,405$ & 85.89 & $5,508,364$ & 84.26 \\
\hline DNA G + C (bp) & $2,729,114$ & 50.49 & $3,507,168$ & 53.65 \\
\hline DNA scaffolds & 51 & 100.00 & 47 & 100.00 \\
\hline Total genes & 4957 & 100.00 & 5880 & 100.00 \\
\hline Protein coding genes & 4822 & 97.28 & 5756 & 97.89 \\
\hline RNA genes & 135 & 2.72 & 124 & 2.11 \\
\hline Pseudo genes & 0 & 0 & 0 & 0 \\
\hline Genes in internal clusters & 1259 & 25.40 & 1709 & 29.06 \\
\hline Genes with function prediction & 3756 & 75.77 & 4458 & 75.82 \\
\hline Genes assigned to COGs & 3092 & 62.38 & 3654 & 62.14 \\
\hline Genes with Pfam domains & 3910 & 78.88 & 4674 & 79.49 \\
\hline Genes with signal peptides & 304 & 6.13 & 350 & 5.95 \\
\hline Genes with transmembrane helices & 1385 & 27.94 & 1658 & 28.20 \\
\hline CRISPR repeats & 0 & 0 & 0 & 0 \\
\hline
\end{tabular}

the same operon. The P. apiarius NRRL B-23460 genome has a HAD subfamily IA hydrolase gene that potentially serves this function, and is located in an operon with other thiamin biosynthesis genes (Fig. 4).

The genes thiD, thiE, and HAD subfamily IA hydrolase gene are found in a highly conserved operon with the thiaminase I gene in the $P$. apiarius NRRL B-23460, $P$. thiaminolyticus NRRL B-4156 and $P$. dendritiformis C454 draft genomes. The operons of all three strains are depicted in Fig. 4 and appear to be regulated by a TPP-binding riboswitch [40]. Thiazole kinase (thiM), which phosphorylates THZ (Fig. 5) [38] is the first gene in the operon, followed by thiD and thiE. The thiamin biosynthesis genes are proceeded by a nucleoside 2-deoxyribosyltransferase, a thymidylate synthase, a SAM-dependent methyltransferase, a Nudix-family hydrolase (YzgD), and thiaminase I (Fig. 4). In the $P$. thiaminolyticus NRRL B-4156 and P. dendritiformis C454 operons, a HAD subfamily IA hydrolase is located directly after the thiaminase I gene. In P. apiarius NRRL B23460, three additional genes are present, which code for a putative transcriptional regulator and two proteins of unknown function (Fig. 4). Since the HAD hydrolase is in the same operon as thiD and thiE, it is likely that it performs the dephosphorylation of TMP. Biochemical studies by Tirrell and colleagues reveal that the YzgD Nudix hydrolase has a HAD domain, which specifically cleaves pyridoxal phosphate, but does not dephosphorylate TMP, TPP, or THZ-P although HMP-P was not tested [41]. The Nudix hydrolase domain is more promiscuous as it is active on nucleoside diphosphates such as CDP-alcohols, ADPcoenzymes, ADP-ribose, TDP-glucose, and some UDP- sugars, restoring the nucleoside monophosphate [41]. It is unclear how this enzyme relates to thiaminase I, but it may play a role in thiamin metabolism. Recently, Nudix hydrolases were discovered clustered with thiamin biosynthesis genes in a few bacterial species as well as in plants and yeast. These Nudix proteins are able to hydrolyze a phosphate from the diphosphate forms of oxothiamin and oxythiamin, thiamin oxidation and hydrolysis products respectively, providing these cells with resistance to these toxic analogs [42]. Due to its location in the paenibacilli genomes, it may serving this protective function, preventing the cell from using toxic thiamin analogs as cofactors instead of TPP.

Cooper et al. described the bacimethrin operon of Clostridium botulinum, which includes the thiaminase I gene [43]. Bacimethrin is a toxic analog of HMP, that when combined with THZ-P forms the antivitamin 2 '-methoxythiamin pyrophosphate, which binds enzymes in place of the TPP cofactor, thus rendering the enzyme nonfunctional [43-45]. The bacimethrin operon consists of a glycosyltransferase (nucleoside 2-deoxyribosyltransferase), thymidylate synthase, methyltransferase, thiaminase I, and pyrimidine kinase, all of which are present in the three paenibacilli (Fig. 4), making it likely that they can produce bacimethrin [43]. In the paenibacilli, ThiD may be bifunctional, serving as a kinase for both pyrimidines, phosphorylating bacimethrin as well as HMP-P. The function of thiaminase I when the antivitamin is produced is not known. Since thiaminase I does not degrade 2'-methoxythiamin pyrophosphate in C. botulinum [43], it is possible that thiaminase I could enhance the effectiveness of this 
Table 5 Number of genes associated with general COG functional categories

\begin{tabular}{|c|c|c|c|}
\hline Code & Value & $\%$ of total & Description \\
\hline J & 219 & $6.30 \%$ & $\begin{array}{l}\text { Translation, ribosomal structure and } \\
\text { biogenesis }\end{array}$ \\
\hline A & 0 & $0.00 \%$ & RNA processing and modification \\
\hline K & 343 & $9.87 \%$ & Transcription \\
\hline L & 98 & $2.82 \%$ & Replication, recombination and repair \\
\hline B & 1 & $0.03 \%$ & Chromatin structure and dynamics \\
\hline $\mathrm{D}$ & 50 & $1.44 \%$ & $\begin{array}{l}\text { Cell cycle control, Cell division, } \\
\text { chromosome partitioning }\end{array}$ \\
\hline V & 110 & $3.16 \%$ & Defense mechanisms \\
\hline $\mathrm{T}$ & 194 & $5.58 \%$ & Signal transduction mechanisms \\
\hline M & 179 & $5.15 \%$ & Cell wall/membrane biogenesis \\
\hline $\mathrm{N}$ & 66 & $1.90 \%$ & Cell motility \\
\hline$U$ & 29 & $0.83 \%$ & Intracellular trafficking and secretion \\
\hline O & 112 & $3.22 \%$ & $\begin{array}{l}\text { Posttranslational modification, protein } \\
\text { turnover, chaperones }\end{array}$ \\
\hline C & 165 & $4.75 \%$ & Energy production and conversion \\
\hline G & 368 & $10.59 \%$ & Carbohydrate transport and metabolism \\
\hline $\mathrm{E}$ & 317 & $9.12 \%$ & Amino acid transport and metabolism \\
\hline $\mathrm{F}$ & 103 & $2.96 \%$ & Nucleotide transport and metabolism \\
\hline $\mathrm{H}$ & 186 & $5.35 \%$ & Coenzyme transport and metabolism \\
\hline | & 127 & $3.65 \%$ & Lipid transport and metabolism \\
\hline$P$ & 213 & $6.13 \%$ & Inorganic ion transport and metabolism \\
\hline Q & 102 & $2.93 \%$ & $\begin{array}{l}\text { Secondary metabolites biosynthesis, } \\
\text { transport and catabolism }\end{array}$ \\
\hline $\mathrm{R}$ & 281 & $8.08 \%$ & General function prediction only \\
\hline S & 186 & $5.35 \%$ & Function unknown \\
\hline- & 1865 & $37.62 \%$ & Not in COGs \\
\hline
\end{tabular}

The total is based on the total number of protein coding genes in the genome of $P$. apiarius NRRL B- 23460

antibiotic against competing bacteria. In contrast to the paenibacilli operons, the C. botulinum thiaminase I operon does not contain genes involved in thiamin biosynthesis and salvage. The C. botulinum operon also contains a putative $A B C$ transporter that is not found in the paenibacilli thiaminase I operons.

Apparently, $P$. dendritiformis $\mathrm{C} 454$ and $P$. thiaminolyticus NRRL B-4156 lack the genomic potential to synthesize both moieties of thiamin. Of the genes involved in thiazole biosynthesis, they both have $d x s$ and nifS, and NRRL B4156 contains thiF. Neither has thiO which is essential for thiazole synthesis in $B$. subtilis. Both lack thiC, so they are unable to convert AIR to HMP. The presence of thiD and thiE in their thiaminase I operons provides the potential to make TMP from environmentally acquired THZ and HMP, a strategy used by other bacteria [46]. ThiM can phosphorylate environmentally derived thiazole alcohol, which can be combined with HMP-P by ThiE (Fig. 5). Like
Table 6 Number of genes associated with general COG functional categories

\begin{tabular}{|c|c|c|c|}
\hline & Value & $\%$ of total & Description \\
\hline$J$ & 248 & $6.03 \%$ & $\begin{array}{l}\text { Translation, ribosomal structure and } \\
\text { biogenesis }\end{array}$ \\
\hline A & 0 & $0.00 \%$ & RNA processing and modification \\
\hline K & 431 & $10.47 \%$ & Transcription \\
\hline L & 112 & $2.72 \%$ & Replication, recombination and repair \\
\hline B & 0 & $0.00 \%$ & Chromatin structure and dynamics \\
\hline D & 59 & $1.43 \%$ & $\begin{array}{l}\text { Cell cycle control, Cell division, } \\
\text { chromosome partitioning }\end{array}$ \\
\hline V & 157 & $3.81 \%$ & Defense mechanisms \\
\hline $\mathrm{T}$ & 263 & $6.39 \%$ & Signal transduction mechanisms \\
\hline M & 224 & $5.44 \%$ & Cell wall/membrane biogenesis \\
\hline N & 63 & $1.53 \%$ & Cell motility \\
\hline$U$ & 28 & $0.68 \%$ & Intracellular trafficking and secretion \\
\hline O & 142 & $3.45 \%$ & $\begin{array}{l}\text { Posttranslational modification, } \\
\text { protein turnover, chaperones }\end{array}$ \\
\hline C & 199 & $4.83 \%$ & Energy production and conversion \\
\hline G & 450 & $10.93 \%$ & Carbohydrate transport and metabolism \\
\hline E & 370 & $8.99 \%$ & Amino acid transport and metabolism \\
\hline $\mathrm{F}$ & 109 & $2.65 \%$ & Nucleotide transport and metabolism \\
\hline $\mathrm{H}$ & 195 & $4.74 \%$ & Coenzyme transport and metabolism \\
\hline | & 139 & $3.38 \%$ & Lipid transport and metabolism \\
\hline$P$ & 246 & $5.98 \%$ & Inorganic ion transport and metabolism \\
\hline Q & 118 & $2.87 \%$ & $\begin{array}{l}\text { Secondary metabolites biosynthesis, } \\
\text { transport and catabolism }\end{array}$ \\
\hline $\mathrm{R}$ & 334 & $8.11 \%$ & General function prediction only \\
\hline$S$ & 202 & $4.91 \%$ & Function unknown \\
\hline - & 2226 & $37.86 \%$ & Not in COGs \\
\hline
\end{tabular}

The total is based on the total number of protein coding genes in the genome of $P$. thiaminolyticus NRRL B-4156

P. apiarius NRRL B-23460, their genomes encode TPK to make TPP. The presence of the thiaminase I in the same operon as thiM, thiD, and thiE suggests a potential role in thiamin salvage. The thiaminase I, acting on thiamin or pyrithiamine (a thiamin analog) [10] would generate HMP* $^{*}$ and a free THZ. We propose that THZ and HMP* could be imported into the cell, phosphorylated by their respective kinases, and combined by ThiE (Fig. 5). TPP is then produced via dephosphorylation by the HAD hydrolase and addition of the pyrophosphate by TPK.

The potential pathways available to the three paenibacilli to salvage thiamin are summarized in Fig. 5. Both $P$. dendritiformis C454 and P. thiaminolyticus NRRL B-4156 genomes code for the intracellular enzyme thiaminase II (TenA), but $P$. apiarius NRRL B-23460 lacks this gene. Thiaminase II catalyzes the base exchange of thiamin with water, but is not a thiaminase I homolog [47]. It functions in the salvage of HMP from base-degraded thiamin [47]. 


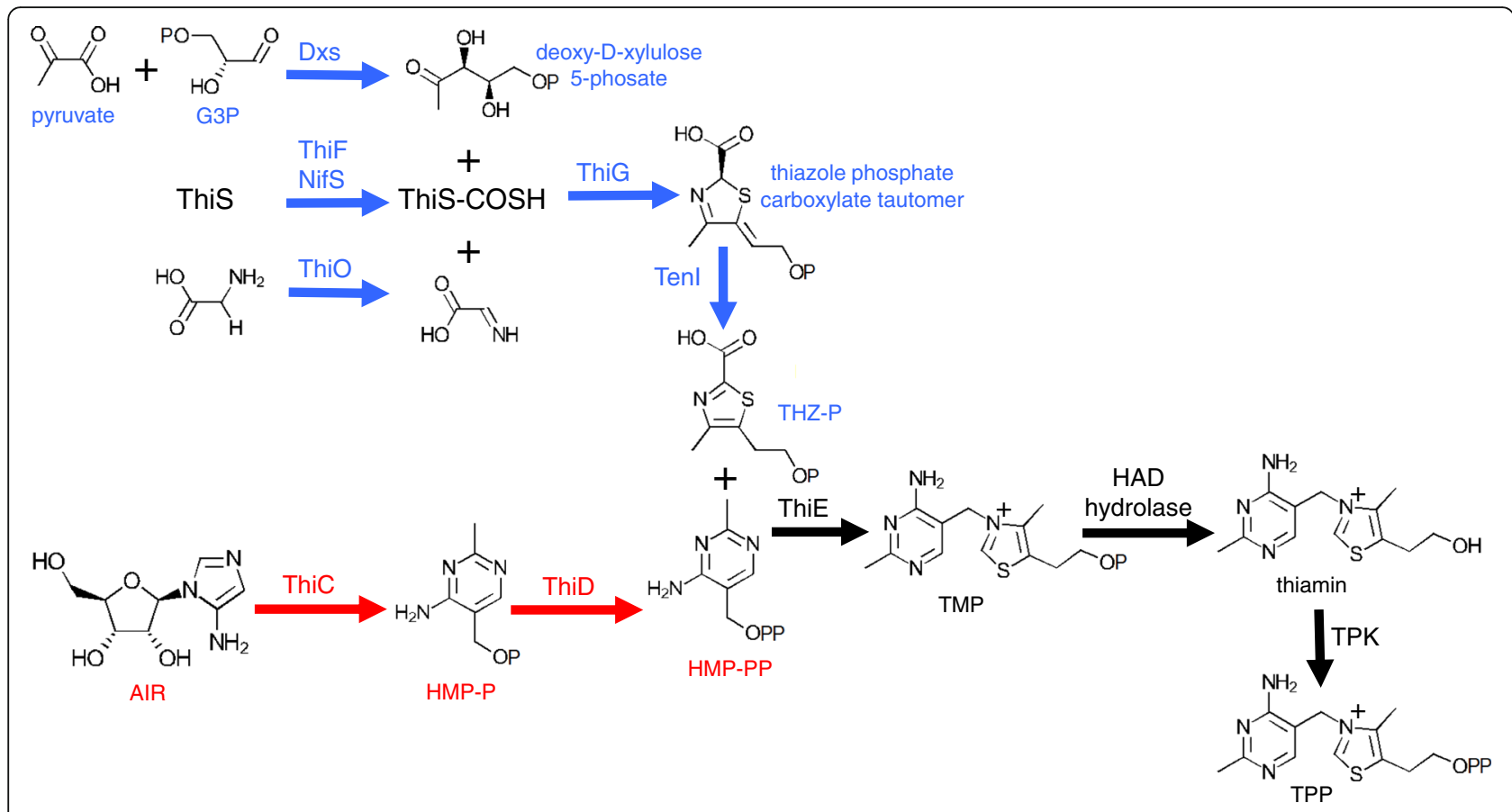

Fig. 3 Predicted thiamin biosynthesis pathway in P. apiarius NRRL B-23460. Pathways involved in thiazole biosynthesis are highlighted in blue and pathways involved in pyrimidine biosynthesis are shown in red. The steps in black correspond to the coupling of the thiazole and pyrimidine moieties, and the formation of the active cofactor TPP

In both genomes that code for this enzyme, TenA appears regulated by a TPP riboswitch. The genomes of all three paenibacilli contain $y \operatorname{lm} B$, which deacetylates basedegraded thiamin forming aminopyrimidine, the preferred substrate for TenA [47] (Fig. 5).

MicroScope identified another TPP riboswitch in all three genomes that appears to regulate a transport system. In all three operons, the riboswitch is preceded by an NMT1/Thi5 domain protein. Thi5 is a yeast protein that converts pyridoxal and histidine to HMP-P, and is a homolog to the ThiY protein found in Bacillus cereus and B. halodurans [48]. ThiY is part of the ThiXYZ ABC transport system putatively involved in the uptake of HMP, as well as in the uptake of base-degraded thiamin [47-49]. In $P$. apiarius NRRL B-23460, this ThiY homolog is followed by a small, 98 amino acid protein with a thiamin-binding domain, suggesting it may have two alternative transporters for this system. However, in the other two paenibacilli genomes, this is followed by a permease, and the ATP-binding protein of the ABC transport system. The other two $\mathrm{ABC}$ transport proteins are found after the small thiamin-binding protein in

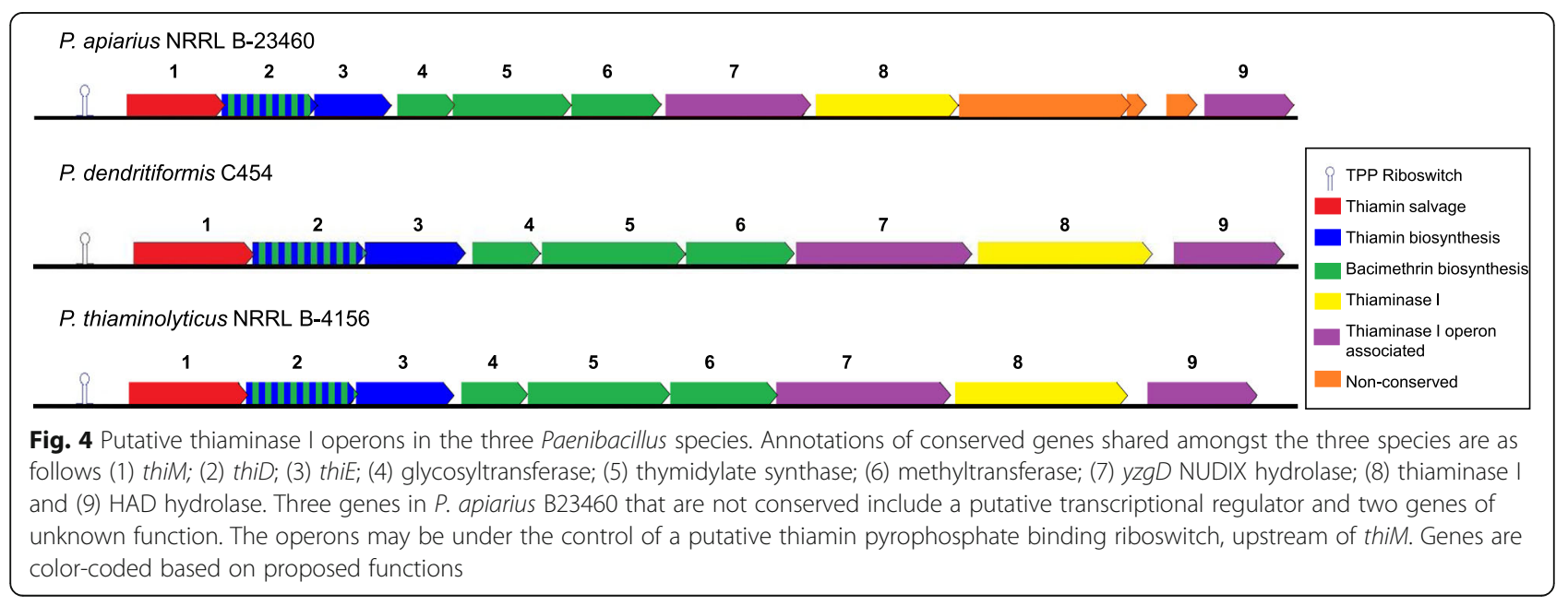




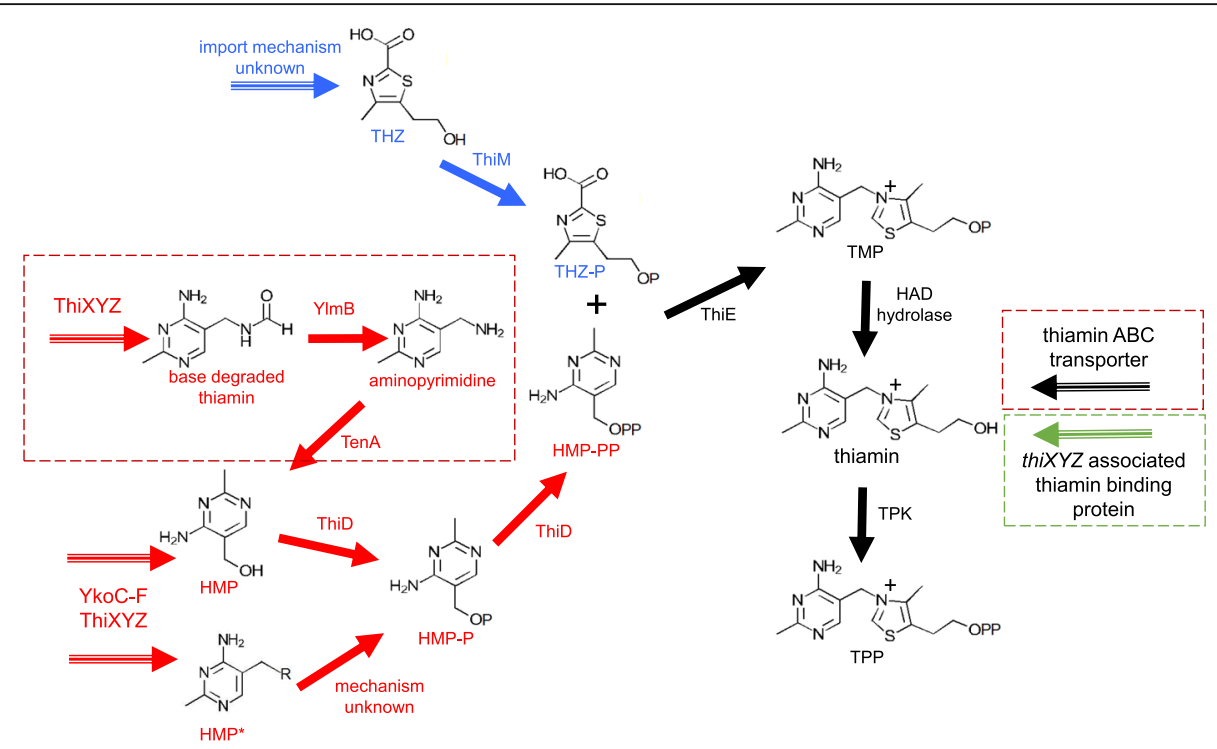

Fig. 5 Predicted thiamin salvage pathways in all three paenibacilli. Pathways involved in thiazole salvage are highlighted in blue and pathways involved in pyrimidine salvage are shown in red. The dotted red boxes are steps unique to $P$. thiaminolyticus NRRL B- 4156 and $P$. dendritiformis C454. Biosynthetic pathways are shown with solid arrows and import pathways are indicated with a striped arrow. The putative importer boxed in green is unique to P. apiarius NRRL B-23460. In all cases, it is not yet understood how THZ enters the cell

NRRL B-23460. This suggests that the genomes of all three paenibacilli contain the ThiXYZ HMP transport system, or a homologous system. In P. thiaminolyticus NRRL B-4156 and P. dendritiformis C454, the system could potentially be dedicated for base-degraded thiamin uptake. The lack of TenA in P. apiarius NRRL B-23460 may explain why it has an additional thiamin-binding protein associated with this transport system, as it cannot use base-degraded thiamin. It is also plausible that this system is involved in the uptake of the HMP* generated by thiaminase I in all three species.

All three paenibacilli contain the $y k o C-F$ operon, which encodes for a putative $A B C$ transport system for HMP uptake [50]. The genes encode for two transmembrane components, an ATPase, and an HMP/thiaminbinding protein YkoF [50]. It is unclear if this system takes up both HMP and thiamin, or is specific for HMP and HMP derivatives, as YkoF binds the HMP moiety and does not appear to have any residues to anchor the thiazole moiety of thiamin. This is in contrast to thiamin binding by TbpA, which also binds the THZ [12]. The YkoF transporter could potentially be used for the uptake of the HMP* derived from thiaminase I breakdown of thiamin and thiamin analogs, as well as free HMP, and possibly base-degraded thiamin as well. MicroScope identified a TPP-binding riboswitch upstream of this operon in all three paenibacilli genomes, suggesting that its expression is regulated by thiamin availability.

The $P$. dendritiformis C454 and P. thiaminolyticus NRRL B-4156 genomes contain another thiamin ABC transport permease in addition to the YkoC-F system.
The thiamin permeases in these two genomes appear to be regulated by TPP riboswitchs and share amino acid sequence similarity with YkoD. Next to the permease is the ATP-binding protein, and the third gene in the operon encodes another transmembrane permease with homology to the cobalt $\mathrm{ABC}$ transporter permease $\mathrm{CbiQ}$. The presence of this permease suggests that the $y k o$ system is only used in HMP and HMP derivative uptake and this system is specific for thiamin, allowing for the two thiamin auxotrophs to acquire intact thiamin from the environment. In all three genomes, ThiW, a transporter specific for THZ [51, 52], was not identified. It is possibly they acquire environmental $\mathrm{THZ}$ via an unknown mechanism.

\section{Conclusions}

The genome sequences of $P$. apiarius NRRL B-23460 and $P$. thiaminolyticus NRRL B-4156 reveal insights into thiamin metabolism of these organisms. While $P$. apiarius NRRL B-23460 appears capable of synthesizing thiamin de novo, P. thiaminolyticus NRRL B-4156 is not, as it lacks the ability to make HMP and THZ. Both organisms apparently phosphorylate thiamin to its active form in a manner rarely used in bacteria, as they can dephosphorylate TMP and then add two phosphates with a pyrophosphokinase to make TPP. The thiaminase I gene is located in a putatively TPP riboswitch-regulated operon with genes for the synthesis of bacimethrin, as well as thiamin biosynthesis and salvage genes. This suggests a potential metabolic role for thiaminase I in thiamin synthesis, especially 
in P. thiaminolyticus NRRL B-4156, which cannot synthesize thiamin precursors. Further, both species appear to have two different systems to take up HMP, both of which appear to be regulated with TPP riboswitches. It is possible that one of these transport systems is specific for HMP* generated from thiaminase I. We suggest that this HMP* compound can be used in thiamin biosynthesis along with THZ scavenged from the breakdown of thiamin. P. thiaminolyticus NRRL B-4156 has the ability to salvage base-degraded thiamin with its intracellular thiaminase II [47], whereas $P$. apiarius NRRL B-23460 does not. This is another method in which $P$. thiaminolyticus can acquire the pyrimidine precursor for thiamin. To further compensate for its auxotrophy, $P$. thiaminolyticus NRRL B-4156 may have a thiamin specific ABC transport system, which is not present in the $P$. apiarius NRRL B-23460 genome. However, NRRL B23460 has a unique thiamin-binding protein encoded for in the thiXYZ operon which $P$. thiaminolyticus NRRL B-4156 lacks. Biochemical and genetic tests need to be conducted to test the hypotheses generated in this study to further elucidate the roles these genes and proteins play in thiamin metabolism.

\section{Abbreviations}

AIR: phospho5-aminoimidazole ribotide; G3P: Glyceraldehyde-3-phosphate; HMP: hydroxymethyl pyrimidine; HMP*: hydroxymethyl pyrimidine-organic nucleophile; HMP-P: hydroxymethyl pyrimidine phosphate; HMPPP: hydroxymethyl pyrimidine pyrophosphate; THZ: thiazole carboxylate; THZ-P: thiazole phosphate carboxylate; TMP: thiamin monophosphate; TPK: thiamin pyrophosphokinase; TPP: thiamin pyrophosphate

\section{Funding}

This research was funded by grants from the National Science Foundation MCB 1244378 and IOS 1354911 .

\section{Authors' contributions}

DS designed the study, assembled the data, performed bioinformatic analyses, constructed phylogenetic trees, and drafted the manuscript. EA conceived of the study, participated in its design and coordination and helped to draft the manuscript. Both authors read and approved the final manuscript.

\section{Competing interests}

The authors declare that they have no competing interests.

\section{Publisher's Note}

Springer Nature remains neutral with regard to jurisdictional claims in published maps and institutional affiliations.

Received: 31 May 2017 Accepted: 25 September 2017

Published online: 03 October 2017

\section{References}

1. Schumpeter EB. The Industrialization of Japan and Manchukuo, 1930-1940, vol. 8. Taylor \& Francis US. 1940;

2. Fujita A. Thiaminase. Adv Enzymol Relat Areas Mol Biol. 1954;15:389-421.

3. Fujita A, Nose Y, Kozuka S, Tashiro T, Ueda K, Sakamoto S. Studies on thiaminase. 1. Activation of thiamine breakdown by organic bases. J Biol Chem. 1952;196:289-95.

4. Kuno Y. Bacillus thiaminolyticus, a new thiamin-decomposing bacterium. Proc J.jn Acad. 1951;27(7):362-5.
5. Abe M, Ito S-i, Kimoto M, Hayashi R, Nishimune T. Molecular studies on thiaminase I. Biochim Biophys Acta Gene Struct Expr. 1987;909(3):213-21.

6. Douthit H, Airth R. Thiaminase I of Bacillus thiaminolyticus. Arch Biochem Biophys. 1966:113(2):331-7.

7. Costello CA, Kelleher NL, Abe M, McLafferty FW, Begley TP. Mechanistic studies on thiaminase I overexpression and identification of the active site nucleophile. J Biol Chem. 1996;271(7):3445-52.

8. Wang L, Wilkins $\mathrm{JH}$, Airth R. Repression of thiaminase I by thiamine and related compounds in Bacillus thiaminolyticus. Can J Microbiol. 1968;14(10):1143-7.

9. Wang L, Airth R. Repression of thiaminase I in Bacillus thiaminolyticus. Biochem Biophys Res Commun. 1967;27(3):325-30.

10. Agee CC, Airth R. Reversible inactivation of thiaminase I of Bacillus thiaminolyticus by its primary substrate, thiamine. J Bacteriol. 1973; 115(3):957-65.

11. Ebata J, Murata K. The purification of thiaminase I produced by Bacillus thiaminolyticus. The. J Vitaminol (Kyoto). 1961;7(2):115-21.

12. Soriano EV, Rajashankar KR, Hanes JW, Bale S, Begley TP, Ealick SE. Structural similarities between thiamin-binding protein and thiaminase-I suggest a common ancestor. Biochemistry. 2008:47(5):1346-57.

13. Katznelson H. Bacillus apiarius, n. sp., An aerobic spore-forming organism isolated from honeybee larvae. J Bacteriol. 1955;70(6):635.

14. Kraft CE, Angert ER. Competition for vitamin B1 (thiamin) structures numerous ecological interactions. Q Rev Biol. 2017;92(2):151-68.

15. Kraft CE, Gordon ER, Angert ER. A Rapid Method for Assaying Thiaminase I Activity in Diverse Biological Samples. PLoS One. 2014;9(3):e92688.

16. McCleary BV, Chick BF. The purification and properties of a thiaminase I enzyme from Nardoo (Marsilea drummondii). Phytochemistry. 1977;16(2):207-13.

17. Kreinbring CA, Remillard SP, Hubbard P, Brodkin HR, Leeper FJ, Hawksley D, Lai EY, Fulton C, Petsko GA, Ringe D: Structure of a eukaryotic thiaminase I. Proc Natl Acad Sci U S A 2014;111(1):137-142.

18. Honeyfield DC, Hinterkopf JP, Brown SB. Isolation of thiaminase-positive bacteria from alewife. Trans Am Fish Soc. 2002;131(1):171-5.

19. Honeyfield DC, Hinterkopf JP, Fitzsimons JD, Tillitt DE, Zajicek JL, Brown SB. Development of thiamine deficiencies and early mortality syndrome in lake trout by feeding experimental and feral fish diets containing thiaminase. J Aquat Anim Health. 2005;17(1):4-12.

20. Richter CA, Evans AN, Wright-Osment MK, Zajicek JL, Heppell SA, Riley SC, Krueger CC, Tillitt DE. Paenibacillus thiaminolyticus is not the cause of thiamine deficiency impeding lake trout (Salvelinus namaycush) recruitment in the Great Lakes. Can J Fish Aquat Sci. 2012;69(6):1056-64.

21. Ouyang J, Pei Z, Lutwick L, Dalal S, Yang L, Cassai N, Sandhu K, Hanna B, Wieczorek RL, Bluth M. Paenibacillus thiaminolyticus: a new cause of human infection, inducing bacteremia in a patient on hemodialysis. Ann Clin Lab Sci. 2008;38(4):393-400.

22. Thomas K, Griffiths F. Natural establishment of thiaminase activity in the alimentary tract of newborn lambs and effects on thiamine status and growth rates. Aust Vet J. 1987;64(7):207-10.

23. Richter CA, Wright-Osment MK, Zajicek JL, Honeyfield DC, Tillitt DE. Quantitative polymerase chain reaction (PCR) assays for a bacterial thiaminase I gene and the thiaminase-producing bacterium Paenibacillus thiaminolyticus. J Aquat Anim Health. 2009;21(4):229-38.

24. Nakamura L. Bacillus thiaminolyticus sp. nov., nom. rev. Int J Syst Evol Microbiol. 1990;40(3):242-6.

25. Nakamura L. Paenibacillus apiarius sp. nov. Int J Syst Evol Microbiol. 1996; 46(3):688-93.

26. Ash C, Priest FG, Collins MD. Molecular identification of rRNA group 3 bacilli (Ash, Farrow, Wallbanks and Collins) using a PCR probe test. Antonie Van Leeuwenhoek. 1993;64(3-4):253-60.

27. Shida O, Takagi H, Kadowaki K, Nakamura LK, Komagata K. Transfer of Bacillus alginolyticus, Bacillus chondroitinus, Bacillus curdlanolyticus, Bacillus glucanolyticus, Bacillus kobensis, and Bacillus thiaminolyticus to the genus Paenibacillus and emended description of the genus Paenibacillus. Int J Syst Evol Microbiol. 1997;47(2):289-98.

28. Schleifer K-H, XIII P. In: De Vos P, Garrity GM, Jones D, Krieg NR, Ludwig W, Rainey FA, Schleifer K-H, Whitman WB, editors. Firmicutes Gibbons and Murray 1978, 5 (Firmacutes [sic] Gibbons and Murray 1978, 5). In: Bergey's Manual of Systematic Bacteriology: Volume Three The Firmicutes. New York, NY: Springer New York; 2009. p. 19-1317.

29. Rippere KE, Tran MT, Yousten AA, Hilu KH, Klein MG. Bacillus popilliae and Bacillus lentimorbus, bacteria causing milky disease in Japanese beetles and related scarab larvae. Int J Syst Evol Microbiol. 1998;48(2):395-402. 
30. liyama K, Otao M, Mori K, Mon H, Lee JM, Kusakabe T, Tashiro K, Asano S-I, Yasunaga-Aoki C. Phylogenetic relationship of Paenibacillus species based on putative replication origin regions and analysis of an yheCD-like sequence found in this region. Biosci Biotechnol Biochem. 2014;78(5):891-7.

31. Price MN, Dehal PS, Arkin AP. FastTree 2-approximately maximumlikelihood trees for large alignments. PLoS One. 2010;5(3):e9490.

32. Sirota-Madi A, Olender T, Helman Y, Brainis I, Finkelshtein A, Roth D, Hagai E, Leshkowitz D, Brodsky L, Galatenko V. Genome sequence of the patternforming social bacterium Paenibacillus dendritiformis C454 chiral morphotype. J Bacteriol. 2012;194(8):2127-8.

33. Bankevich A, Nurk S, Antipov D, Gurevich AA, Dvorkin M, Kulikov AS, Lesin VM, Nikolenko SI, Pham S, Prjibelski AD. SPAdes: a new genome assembly algorithm and its applications to single-cell sequencing. J Comput Biol. 2012;19(5):455-77.

34. Parks DH, Imelfort M, Skennerton CT, Hugenholtz P, Tyson GW. CheckM: assessing the quality of microbial genomes recovered from isolates, single cells, and metagenomes. Genome Res. 2015;25(7):1043-55.

35. Vallenet D, Belda E, Calteau A, Cruveiller S, Engelen S, Lajus A, Le Fèvre F, Longin C, Mornico D, Roche D: MicroScope-an integrated microbial resource for the curation and comparative analysis of genomic and metabolic data. Nucleic Acids Res. 2012:gks1194.

36. Markowitz VM, Chen I-MA, Palaniappan K, Chu K, Szeto E, Grechkin Y, Ratner A, Jacob B, Huang J, Williams P. IMG: the integrated microbial genomes database and comparative analysis system. Nucleic Acids Res. 2012;40(D1):D115-22.

37. Harwood CR, Cutting SM. Molecular biological methods for Bacillus. Chichester. New York: Wiley; 1990

38. Jurgenson CT, Begley TP, Ealick SE. The structural and biochemical foundations of thiamin biosynthesis. Annu Rev Biochem. 2009;78:569-603.

39. Hasnain G, Roje S, Sa N, Zallot R, Ziemak MJ, de Crécy-Lagard V, Gregory JF, Hanson AD. Bacterial and plant HAD enzymes catalyse a missing phosphatase step in thiamin diphosphate biosynthesis. Biochem J. 2016:473(2):157-66.

40. Mironov AS, Gusarov I, Rafikov R, Lopez LE, Shatalin K, Kreneva RA Perumov DA, Nudler E. Sensing small molecules by nascent RNA: a mechanism to control transcription in bacteria. Cell. 2002;111(5):747-56.

41. Tirrell IM, Wall JL, Daley CJ, Denial SJ, Tennis FG, Galens KG, O'Handley SF. YZGD from Paenibacillus thiaminolyticus, a pyridoxal phosphatase of the HAD (haloacid dehalogenase) superfamily and a versatile member of the Nudix (nucleoside diphosphate $x$ ) hydrolase superfamily. Biochem J. 2006; 394(3):665-74

42. Goyer A, Hasnain G, Frelin O, Ralat MA, Gregory JF, Hanson AD. A crosskingdom Nudix enzyme that pre-empts damage in thiamin metabolism. Biochem J. 2013:454(3):533-42.

43. Cooper LE. O'Leary SnE, Begley TP: Biosynthesis of a Thiamin Antivitamin in Clostridium botulinum. Biochemistry. 2014;53(14):2215-7.

44. Reddick JJ, Saha S, Lee J-k, Melnick JS, Perkins J, Begley TP. The mechanism of action of bacimethrin, a naturally occurring thiamin antimetabolite. Bioorg Med Chem Lett. 2001;11(17):2245-8.

45. Zilles JL, Croal LR, Downs DM. Action of the thiamine antagonist bacimethrin on thiamine biosynthesis. J Bacteriol. 2000;182(19):5606-10.

46. Karunakaran R, Ebert K, Harvey S, Leonard M, Ramachandran V, Poole P. Thiamine is synthesized by a salvage pathway in Rhizobium leguminosarum bv. viciae strain 3841. J Bacteriol. 2006;188(18):6661-8.

47. Jenkins $A H$, Schyns $G$, Potot $S$, Sun $G$, Begley TP. A new thiamin salvage pathway. Nat Chem Biol. 2007:3(8):492-7.

48. Bale S, Rajashankar KR, Perry K, Begley TP, Ealick SE. HMP binding protein ThiY and HMP-P synthase THI5 are structural homologues. Biochemistry. 2010;49(41):8929-36

49. Rodionov DA, Vitreschak AG, Mironov AA, Gelfand MS. Comparative genomics of thiamin biosynthesis in procaryotes. J Biol Chem. 2002; 277(50):48949-59.

50. Devedjiev Y, Surendranath Y, Derewenda U, Gabrys A, Cooper DR, Zhang R-g Lezondra L, Joachimiak A, Derewenda ZS. The structure and ligand binding properties of the $B$. subtilis YkoF gene product, a member of a novel family of thiamin/HMP-binding proteins. J Mol Biol. 2004;343(2):395-406.

51. Rodionov DA, Hebbeln P, Eudes A, Ter Beek J, Rodionova IA, Erkens GB, Slotboom DJ, Gelfand MS, Osterman AL, Hanson AD. A novel class of modular transporters for vitamins in prokaryotes. J Bacteriol. 2009;191(1):42-51.

52. Anderson LN, Koech PK, Plymale AE, Landorf EV, Konopka A, Collart FR, Lipton MS, Romine MF, Wright AT. Live cell discovery of microbial vitamin transport and enzyme-cofactor interactions. ACS Chem Biol. 2015:11(2):345-54

53. Field D, Garrity G, Gray T, Morrison N, Selengut J, Sterk P, Tatusova T, Thomson N, Allen MJ, Angiuoli SV. The minimum information about a genome sequence (MIGS) specification. Nat Biotechnol. 2008;26(5):541-7.

54. Woese CR, Kandler O, Wheelis ML. Towards a natural system of organisms: proposal for the domains Archaea, Bacteria, and Eucarya. Proc Natl Acad Sci U S A. 1990;87:4576-9.

55. Gibbons N, Murray R. Proposals concerning the higher taxa of bacteria. Int J Syst Evol Microbiol. 1978;28:1-6.

56. Euzéby J. List of new names and new combinations previously effectively, but not validly, published. Int J Syst Evol Microbiol. 2006;56:925-7.

57. Ludwig WSK, Whitman WB. Class I. Bacilli class nov. In: De Vos P, Garrity G, Jones D, Krieg NR, Ludwig W, Rainey FA, Schleifer KH, Whitman WB, editors. Bergey's manual of systematic bacteriology, Second Edition, Volume 3. New York: Springer; 2009. p. 19-20.

58. Skerman VBD, McGOWAN V, Sneath PHA. Approved lists of bacterial names. Int J Syst Bacteriol. 1980;30:255-420.

59. Validation List no. 51. Validation of the publication of new names and new combinations previously effectively published outside the IJSB. Int J Syst Bacteriol. 1994:44:852.

60. Ashburner M, Ball CA, Blake JA, Botstein D, Butler H, Cherry JM, Davis AP, Dolinski K, Dwight SS, Eppig JT. Gene Ontology: tool for the unification of biology. Nat Genet. 2000;25(1):25-9.

\section{Submit your next manuscript to BioMed Central and we will help you at every step:}

- We accept pre-submission inquiries

- Our selector tool helps you to find the most relevant journal

- We provide round the clock customer support

- Convenient online submission

- Thorough peer review

- Inclusion in PubMed and all major indexing services

- Maximum visibility for your research

Submit your manuscript at www.biomedcentral.com/submit
C) Biomed Central 